\title{
3D vibration and stress analysis of insulators
}

\author{
D. Mazur ${ }^{1}$ and M. Trojnar ${ }^{1}$ \\ ${ }^{1}$ Department of Electrical and Computer Engineering Fundamentals \\ Rzeszow University of Technology, \\ ul. W. Pola 2, 35-959 Rzeszów (Poland) \\ phone:+48 17 8651298, fax:+48 17 8542088, e-mail: mazur@prz.rzeszow.pl, trojnar@prz.rzeszow.pl
}

\begin{abstract}
Numerous dedicated computer packages are of much help at insulator designing process. Making a digital model of an insulator and then performing computer simulation for the phenomena occurring both inside and outside of it, becomes nowadays a vital information source on the insulator behavior at established (both given and analyzed) operational conditions. Such a process appears to be necessary at the stage of insulator design process. The computer simulation results can verify the data obtained during actual insulator operation or laboratory tests, which make it possible to do suitable adjustments still at the design stage in order to include some innovative solutions, operational features, improvements as well as to get some economical advantages resulting from them.

Selected problems associated with static electricity and mechanical phenomena occurring at insulator operation have been addressed in this paper. The calculations have been made with ANSYS Multipurpose Finite Elements Method Package as well as the MSC/PATRAN v.8.5, the latter used mainly for mechanical purposes [6].
\end{abstract}

\section{Key words}

Insulator, computer simulation, Finite Element Method, electrostatic and mechanical phenomena in insulators

\section{Introduction}

Rapid development of Informatics, which gives numerous specialized computer packages that augment both scientists and engineers at their work, allows them to make computer model of insulators, and subsequently test them both for electrical and mechanical strength. These specialized computer packages are of much help at insulator design process (so they are at studying the phenomena which occur both within the insulator itself as well as in its vicinity), as suitability of insulators for the operation in certain actual conditions is considered on the basis of data collected at their actual operation or laboratory tests. Although the data gathered during insulator operation are of much value, they are difficult to obtain and are both cost and time consuming. On the other hand to get some important information on insulator behavior quickly, laboratory tests are conducted, and then, on the basis of them, necessary corrections in the design process done. Unfortunately, not all important conditions (e.g. long-term pollution accumulation on the insulator) can be easily reconstructed experimentally.

This is where the specialized computer packages meet both the designer's and scientists' needs.

\section{Analysis of the insulators}

Pillars and insulators are applied for the construction of power lines. They assure, except for required clearances between each separate wires of the same or other lines, or to ground buildings, necessary mechanical and electrical resistance of the system against the action of environmental factors. The electrical strength is influenced markedly by environmental factors, i.e. pressure, temperature and air humidity, natural or industrial pollution. The mechanical strength in turn is influenced by, but not limited to, its design, material it is made of (as well as the quality of manufacture) [7].

\section{A. Modeling of electrostatic phenomena}

The main factor causing adhesion of impurities to an insulator are both pollution and moisture. The pollution contents of atmosphere varies depending on geographical region. Areas densely industrialized and urbanized, as mines, large power plants, steelworks, refineries and other industrial complexes, belong to those regions where air is the most heavily polluted. On the other hand there are woodlands and rural areas, where air is polluted in the slightest amount. However this is not the rule, as the latter could be also polluted due to the proliferation of gaseous pollutants originating from tall smoke stacks, which could cover the distance up to tens of kilometers.

These pollutants itself generally do not pose any direct danger to electric insulation, providing that they are not liquids, which could form conducting coating over the insulator surface. As for the solid and gaseous impurities, they become materials of better conducting properties after absorbing some moisture. Moistening of sediments on aerial insulators is caused by rainfall, drizzle, fog, thawing ice or snow.

Intensified ionization and corona discharges can be observed around polluted insulators at relatively low moisture. This is caused by the loss of the superficial 
smoothness and increase of current leakage (as compared to the regular environmental conditions). Energetic phenomena occurring within the sediment layer play decisive role in development of dirt-associated discharges dominated by leak currents. The superficial density of leak currents becomes less and less homogenous, due to varying diameter of an insulator as well as to varying thickness of sediment layer, its consistency and nonuniform moisturizing, which make the dirt layer to dry in an non-uniform fashion. The original non-uniform spots become more and more prominent with time, as the power emitted - proportional to $\mathrm{RI}^{2}$ - is greater in those spots where the surface of an insulator is drier, and thus of greater resistance as compared to other spots. The accumulated dirt on insulators influences the flow of the conduction current and thus adds to the energy loss.

As the dirt layer accumulated over the insulator surface is an important factor which determines both, the distribution of tangential component of the electric field vector and the strength of an insulator, it is purposeful to study this issue, which is continually being effected for years. The calculation results are valuable at insulator design optimization and operation.

The calculations have been performed using ANSYS Multipurpose Finite Elements Method Package. Several sheds of insulator have been selected as the object for the purpose of this analysis (see Fig. 1) as well as an aggregate of included in air, between two electrodes of known potential values $(15 \mathrm{kV}, 0 \mathrm{kV})$. Neuman condition has been applied on the boundary. Porcelain has been assumed as a material the insulator was made (porcelains permitivity value of $\varepsilon_{p}=6 \varepsilon_{o}$ has been assumed for the calculations) [2,3].

Clean insulator (without the dirt layer) as well as the one covered with dirt layer distributed uniformly all over the surface, have been assumed for these considerations. For preliminary simplification, a dielectric layer of conductivity of $\sigma$ has been applied in place of resistive conducting (dirt) layer, which are equivalent in such way that the permitivity of the first one $\varepsilon_{\delta}=\sigma / \omega$ (relative permitivity of layer of $\operatorname{dirt} \varepsilon_{z}=\varepsilon_{\delta} / \varepsilon_{o}$. These considerations form the preliminary stage for further studies where calculations with included active conducting (resistive) layer, can be performed. The main reason for adopting the aforementioned simplifications, as it appeared during the calculations performed further on, was that it was impossible to declare complex values within ANSYS package for the electrostatic analysis. This can be managed in the future by using other professional packages as e.g. OPERA [4]. Typical potential distribution has been shown in Fig. 1.

The voltage over on insulator is non-uniformly distributed. For example the voltage drops by $50 \%$ over the first of the two sheds (counting form the high voltage wire side). So the electric field strength in the ferrule region is great, which causes incomplete discharges in the area where the ferrule is connected to the insulator. These discharges are not much detrimental for ceramic insulators. However incomplete discharges which occur at composite insulator ferrule, cause the dielectric material to erode which leads to the tightness loss. Then the moisture penetrates the interior, deepening the erosive effect which may lead to insulator rupture $[9,10]$. The simplest way to reduce the risk of pollution flashover is to increase the insulator leak path. This can be accomplished by selection of insulators of a more complex shape (more densely distributed sheds with ribs under them) or by the insulators of greater assembly length.

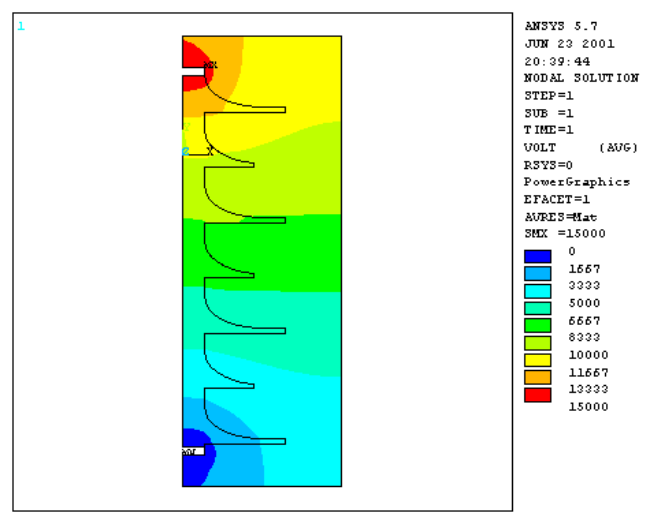

Fig. 1. Distribution of potential on insulator

There are however limitations associated with both options; the first results in shortening of too much developed leak path by partial arcs, the other one causes the inter-phase clearances in power lines to increase, which is an economic problem. That is why adjusting insulator shape (optimization) to polluted conditions, is so much important. The Polish Standard PN IEC 815 „Guidelines for the selection of insulators for the operation in polluted conditions" includes only some general guidelines for insulator manufacturers. The existing mathematical models of the pollution flashover as two-dimensional and do not consider the third dimension and it is difficult to define the distribution of the pollution. However, the simulation starts with uniform pollution distribution on each separate shed, and then non-uniform pollution is introduced.

\section{B. Modeling of mechanical phenomena}

Performing mechanical tests with rupture load in a routine manner forms a basis for the compliance of an insulator lot to the requirements. The crucial property which determines the operational characteristics of insulators is their mechanical strength. It depends not only on the insulator design (quality, type), but also on the ceramic material being used, engineering level as well as the stability (quality) of the manufacturing. It appears that the ferrules, fasteners and type of binding agent applied to bind the ferrules to ceramic parts, are also of much influence here [7].

For these reasons, it is desirable to monitor and analyze the strength of insulators being manufactured on a regular basis. In practice it is accomplished by application of a test load to $100 \%$ of insulators in order to detect and reject the faulty pieces. Also rupture tests are being performed within the scope of control / acceptance tests. 
As the laboratory tests were unavailable, free vibration analysis of a ceramic insulator has been performed both at no load and $10 \mathrm{kN}$ load conditions. The calculations have been performed with MSC PATRAN v.8.5 system.

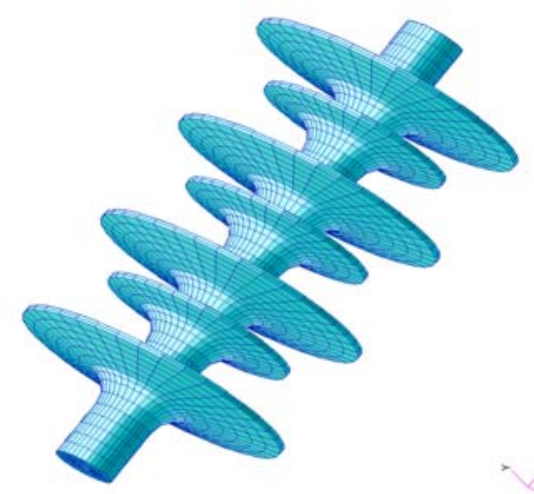

Fig. 2. 3D insulator model made in MSC/PATRAN

When looking the results obtained during the calculations of the free vibrations of an insulator one can come to the conclusion that the free vibration frequencies are not susceptible to tension. The displacement versus load is a linear relation.

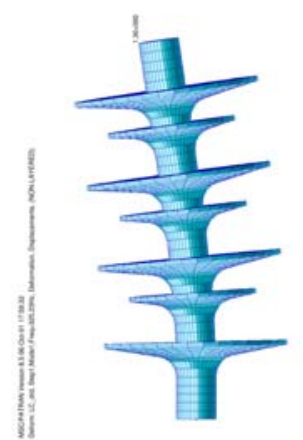

Fig. 3

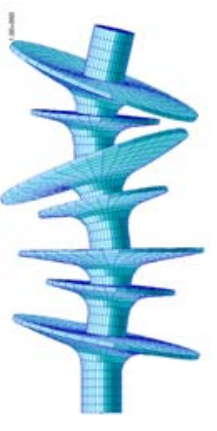

Fig. 5

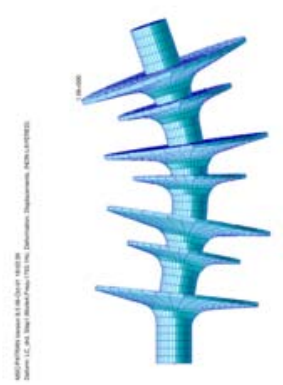

Fig. 4

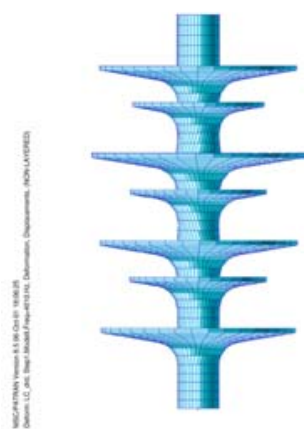

Fig. 6

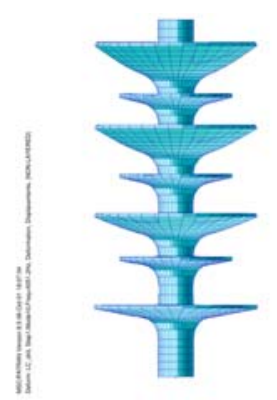

Fig. 7
TABLE I. Free vibrations of an insulator at no load and $10 \mathrm{kN}$ load conditions

\begin{tabular}{|c|c|c|c|}
\hline & $\begin{array}{c}\text { Harmonic } \\
\text { vibration order }\end{array}$ & $\begin{array}{l}\text { No load } \\
\mathrm{f}[\mathrm{Hz}] \\
\end{array}$ & $\begin{array}{l}60 \mathrm{kN} \text { load } \\
\mathrm{f}[\mathrm{Hz}]\end{array}$ \\
\hline \multirow[t]{2}{*}{ Fig. 3} & $\begin{array}{c}1^{\text {st }} \text { transverse } \\
\text { vibration harmonic }\end{array}$ & 353,23 & 345,48 \\
\hline & $\begin{array}{c}1^{\text {st }} \text { torsional } \\
\text { vibration harmonic }\end{array}$ & 932,27 & 932,1 \\
\hline \multirow[t]{2}{*}{ Fig. 4} & $\begin{array}{c}2^{\text {nd }} \text { transverse } \\
\text { vibration harmonic }\end{array}$ & 1753,1 & 1772,2 \\
\hline & $\begin{array}{c}2^{\text {nd }} \text { torsional } \\
\text { vibration harmoni }\end{array}$ & 2666,7 & 2666,4 \\
\hline Fig. 5 & $\begin{array}{l}3^{\text {rd }} \text { transverse } \\
\text { vibration harm }\end{array}$ & 3713,8 & 3721,9 \\
\hline Fig. 6 & $\begin{array}{c}3^{\text {rd }} \text { torsional } \\
\text { vibration harmonic }\end{array}$ & 4010,0 & 4009,6 \\
\hline Fig. 7 & $\begin{array}{c}1^{\text {st }} \text { longitudinal } \\
\text { vibration harmonic }\end{array}$ & 4051,2 & 4049,1 \\
\hline
\end{tabular}

\section{Insulator static calculations}

The mechanical strength is equally important as the electrical one. An increase in number of damaged insulators has been observed in the eighties. The damages were caused by intrinsic rupture of insulator stems and were of seasonal nature. Insulators break after varying service periods. According to [5] the average service life used to fall within the limits of 17.4 through 22.2 years. The simulation results show that the greatest risk of breaking insulators occurs at the stem, which can be determined by calculation of stresses. a)

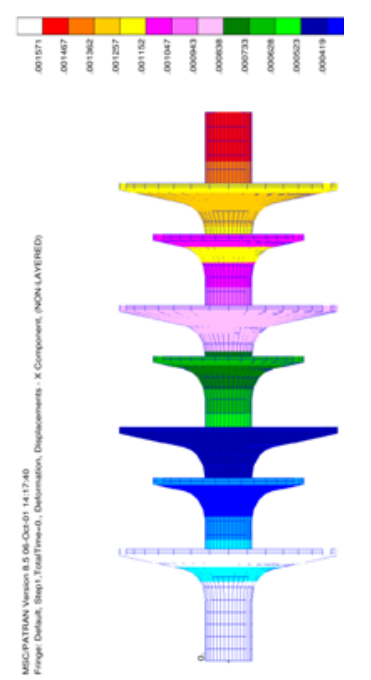

b)

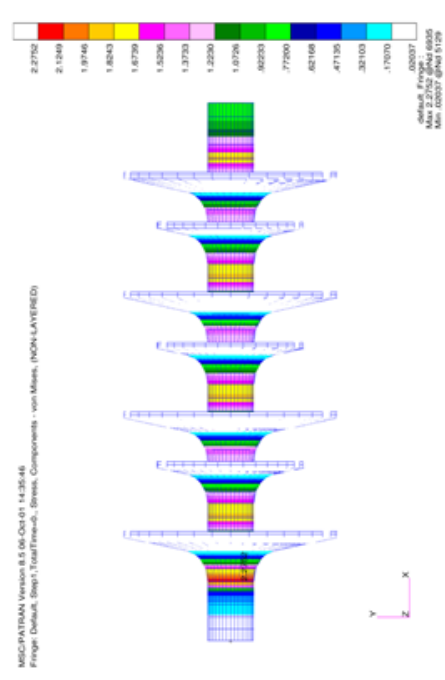

Fig. 8 Static calculations of displacements and stresses within 3D insulator model in MSC/PATRAN system: a) displacements, b) stresses.

The intrinsic ruptures of insulators are still present and still are of seasonal nature (they break mostly in November through April). It can be concluded that, winter seasons, low temperatures, setting snow on insulators are main reasons to cause insulators breakage. It would be interesting to simulate the influence of thermal phenomena (low and high temperatures) on insulator operation [8]. 


\section{Damaged insulator}

Calculations of lesser tensions under loads $60 \mathrm{kN}$ for model of insulator with damaged one shed (Fig. 9a) and calculations of circumferential tensions are presented in pictures below (Fig.10 and Fig.11). Map of deformation along axis $Z$ put on deformed model is presented in Fig.9b. On this picture is apparently, that cracks in trude on oneself and bottom half has displacements on negative and minus half on plus direction of axis $Z$. a)

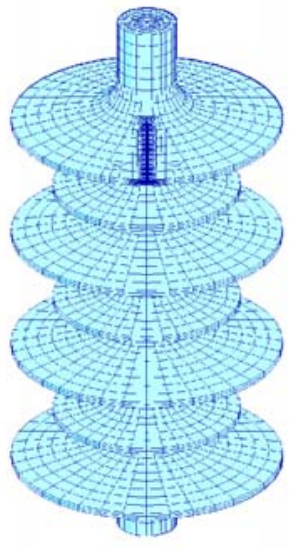

b)

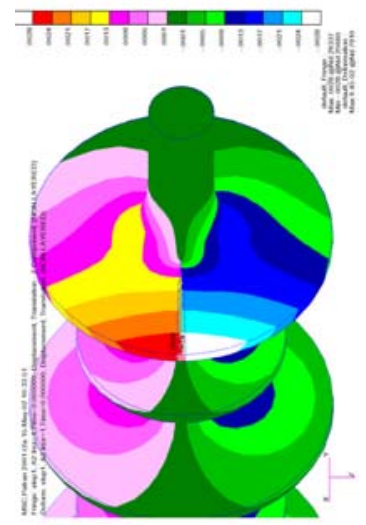

Fig. 9. a) Model of insulator with broken one shed and stresses under loads $60 \mathrm{kN}$.

b) Map of deformation along axis $\mathrm{Z}$ put on deformed model

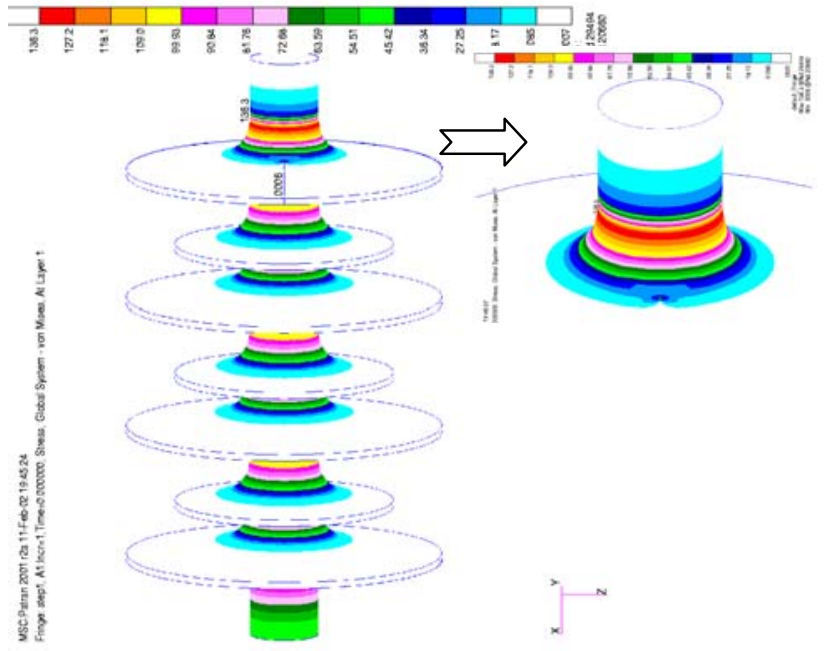

Fig. 10. Lesser Tensions under loads $60 \mathrm{kN}$

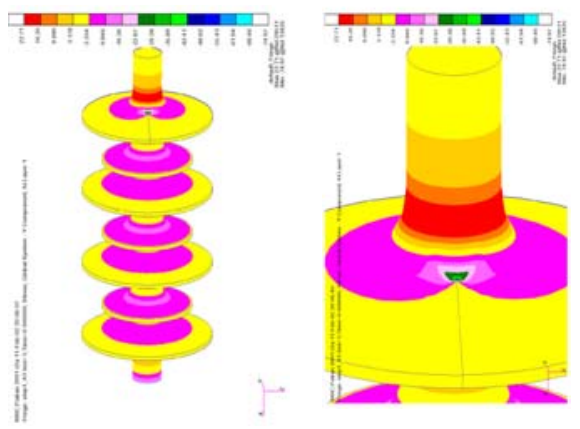

Fig. 11. Circumferential Tensions

\section{Conclusion}

Possibilities of application of professional FEA packages for the analysis of selected electrostatic and mechanical problems in insulators have been presented in this paper. For the simulation research, commercial field packages using FEM as ANSYS 5.7 and MSC/PATRAN 8.5 have been used. In both programs, insulator system geometry of the objects under consideration have been performed in preprocessor. Then the triangular mesh has been generated. In order to obtain accurate results in particularly interesting insulator areas, increasing mesh density has been applied (both manually and automatically). Following the introduction of, parameters typical for dielectric materials (insulator, air, pollution layer), potentials of metal components and boundary conditions, given model has been subject to analysis with the use of ANSYS and MSC/PATRAN solver. In the future, the further stage of modeling mechanical phenomena will be studying defective insulators and thermal simulation, performed for other than porcelain material properties.

\section{References}

[1] K. L. Chrzan, J. Andino and R. Twarowski, "Effects of acid rain on outdoor insulators" Int. Conf. on Advances in Processing, Testing and Application of Dielectric Mat. APTADM'2001, pp. 212-216

[2] S. Chakravorti, and H. Steinbigler, "Boundary Element Studies on Insulator Shape and Electric Field around HV Insulators with or without Pollution," IEEE Trans. Electrical Insulation, Vol. 7, April 2000, pp. 169-176.

[3] O. A. De La, A. and R. S. Gorur, "Flashover of Contaminated Non-Ceramic Outdoor Insulators in a Wet Atmosphere", IEEE Trans. Electrical Insulation, Vol. 5, No. 6, December 1998, pp. 814-823.

[4] W. Que and S. A. Sebo: "Electric Field and Potential Distributions along Dry and Clean Non-Ceramic Insulators, http://www.integratedsoft.com/Papers/research/Coulomb_H igh_Voltage_paper.pdf

[5] D. Duda, Z. Gacek and W. Kliś, „Lokalny wskaźnik uszkodzeń mechanicznych izolatorów dhugopniowych w liniach napowietrznych 110kV", VI Ogólnopolska Konferencja Naukowo-Techniczna „Napowietrzna izolacja wysokonapieciowa $w$ elektroenergetyce NIWE 2000", Bielsko-Biała, 2000, str. 213-218

[6] D. Mazur and M. Trojnar, „Modelowanie wybranych zagadnień mechanicznych w izolatorach", XI Międzynarodowe Sympozjum Dynamiki konstrukcji, Arłamów, 25-27 września 2002

[7] Z. Pohl, „Izolatory elektroenergetyczne”, Oficyna Wydawnicza Politechniki Wroclawskiej, Wroclaw, 1995

[8] A. Skopec, J. Wańkowicz and B. Sikorski, "Electric Field Calculation for an Axially-symmetric Insulator with Surface Contamination". IEEE Transaction on Dielectrics and Electrical Insulation Vol.1 No.2, April 1994, s.332-339.

[9] T. Zhao and G. Comber, "Calculation of Electric Field and Potential Distribution along Nonceramic Insulators Considering the Effects of Conductors and Transmission Towers," IEEE Trans. Power Delivery, Vol. 15, No. 1, January 2000, pp. 313-318.

[10] E. Krupa and A. Majewski „Analiza rozkładu wytrzymałości mechanicznej izolatorów liniowych produkcji ZPE ZAPEL S.A.”, NIWE 2000”, Bielsko-Biała, s. $117-123,2000$ 